\title{
Chemistry Lab Reports At University: To Write Or Not To Write
}

Ismin Izwani Zainol Abidin, Cyberjaya University College of Medical Sciences, Malaysia Sharifah Fauziah Hanim Syed Zain, Cyberjaya University College of Medical Sciences, Malaysia Farah Eliza Mohamad Rasidi, Cyberjaya University College of Medical Sciences, Malaysia Saheera Kamarzaman, Cyberjaya University College of Medical Sciences, Malaysia

\begin{abstract}
The writing of lab reports is part and parcel of Chemistry in higher institutions around the world, with almost similar formats and procedures. This paper looks at the practice of writing lab reports in Chemistry for two cohorts of the pre-university programme, as well as four cohorts of the first and second years of the Bachelor of Pharmacy programme. The study also compares lab reports written by students in the respective courses to investigate the skills and knowledge obtained by students, and the value of assessment marks given on students' reports. The effectiveness of the lab report in contributing to their knowledge during the final exam is also explored. Initial findings showed that lab reports for undergraduate Pharmacy programme can become redundant with the existence of the lab manual, hence questioning the validity of the assessment marks. All experiments tested theories with generally known results which are explained in textbooks and/or on the Internet, which disputes the need of a lab report. Additionally, students found questions reflecting higher levels of Bloom's taxonomy more difficult to handle, with an added challenge to complete the Discussion section of the lab report, despite sufficient discussions and lectures. The study ends with suggestions for alternative methods of writing lab reports - to restructure, revise and improve.
\end{abstract}

Keywords: Chemistry; Lab Report; Assessment Marks; Pharmacy Students

\section{INTRODUCTION}

$\mathrm{t}$ is almost impossible to find a science-based course without its sidekick laboratory practical sessions. It is widely accepted that Chemistry and its laboratory work almost cannot operate without the other, and cannot be seen in isolation. Lack of laboratory sessions sometimes indicates to students that Chemistry is very abstract and theoretical, which should be avoided at all costs. Students in secondary schools in Malaysia are exposed to the objectives of the Chemistry curriculum, among which are to "enable students to acquire scientific and thinking skills, [as well as] apply knowledge and skills in a creative and critical manner for problem solving and decision-making" (Ministry of Education Malaysia, 2005, p. 2). They too are exposed to skills and techniques related to the conduct of experiments in a scientific way. Upon entering higher institutions, students - especially those pursuing medical and pharmacy-related courses - would expect a continuation of the practical lab sessions they had had in school, and that lectures and lab sessions are related and taught concurrently. This also brings advantage to the higher institution, that their students already have experienced laboratory work in schools, hence helping to facilitate wider laboratory knowledge, building students' confidence, improving understanding and more effective contribution to the overall learning in the course.

Carnduff and Reid, as cited by Reid and Shah (2007, p. 176), outline the need for laboratory work for higher education in three main areas; (a) practical skills, - with consideration on safety, hazards, risk assessment, procedures, instruments, observation of methods; (b) transferable skills, - as well as team work, organisation, time management, communication, presentation, information retrieval, data processing, numeracy, designing strategies, problem solving; and (c) intellectual stimulation, - with elements related to the real world, promoting interest for Chemistry. 
The skill of writing a lab report is not foreign to students either. A good lab report does more than merely present data; it demonstrates the students' comprehension of the concepts behind the experiment and the data obtained. To record and reproduce expected results is not enough; students should be able to identify how and why differences occur, and be able to explain how the data was affected by the experiment. Students are also expected to show their understanding of the principles that the experiment is designed to examine, all of which require students' organisation of thoughts and ideas. Being able to communicate experiment results effectively, in acceptable scientific style, is strongly recommended as it is a skill that students must demonstrate (Aurora, 2010; Olney, 1997; Rowell, 1997; Rudd, 2002). Meaningful learning, as advocated by many education theories, for example Cognitivism and Constructivism theories, (Atherton, 2010; Brooks \& Brooks, 1999; Cooper, 1993; Hein, 1991) can be made possible in the laboratory as students construct understanding based on the findings, critically evaluating data and supporting claims with evidence.

\section{Objectives}

This study aims to investigate the benefits of writing Chemistry lab reports among pre-university and undergraduate students. It also aims to determine the value of assessment in Chemistry lab reports among preuniversity and undergraduate Pharmacy students.

\section{Research Questions}

In pursuit of the objectives stated above, the following research questions were employed:

1. To what extent is writing Chemistry lab reports helpful to pre-university and undergraduate Pharmacy students?

2. Does writing Chemistry lab reports assist pre-university and undergraduate Pharmacy students in disciplinary writing and critical analysis?

3. Is the mark given for a lab report a fair assessment of pre-university and undergraduate Pharmacy students' work?

\section{Statement of Problem}

Rudd, Greenbowe and Hand (2002) stressed that students of Chemistry at the early tertiary level spend time completing laboratory activities instead of trying to make quality observations or develop connections between experimental work and the related theory. This is similar to Reid and Shah (2007), who also mentioned that laboratories at the undergraduate level do not promote the skills of "observation, measurement, prediction, interpretation" (p.177), nor show how a theory is confirmed, all of which are critical lab skills students need to develop. Furthermore, only a handful of students spent time reading their lab manuals prior to entering the laboratory, and the only security is for the lecturer to include pre-lab assignments to ensure reading was done.

Chemistry at the pre-university level and undergraduate Pharmacy programme involve the use of lab manuals to guide students and help them to prepare, with expected results already stated. As all experiments test already-proven theories and focus on confirming concepts already taught, the development of conceptual understanding of a topic is limited. The discussion in the reports shows that they fail or are weak to link their observations and data collected, or merely re-stating what they found in textbooks or the internet. At times the lab sessions are a means to test students' ability to follow instructions, not developing understanding of chemistry (Rovira-Figueroa, 2009; Rudd, Greenbowe \& Hand, 2002). Questions that require students to "analyse", "explain" or "justify", all of which involve higher-order thinking in the Bloom's taxonomy (Bloom, 1956; Bloom, Hastings, \& Mandaus, 1971; Churches, 2008; Joyce, Weil \& Calhoun, 2009; Seddon, 1978), are handled with difficulty and in some responses, some students purely regurgitated facts they memorised. Gallet (1998) stressed that experiments based on "cookbook formula" (p.72) leave students without imagination and initiative, and neither include students' involvement in the decision making process nor give room for creating hypothesis. As future pharmacists, they must develop skills in using and testing of ideas and information beyond merely comprehension, to the best interests of the course and themselves. 
Chemistry Lab is a standalone course at the pre-university programme and constitutes one credit unit; $60 \%$ of assessment is based on the lab reports that students produce. Students are given pre-lab questions and required to transfer information from the lab manual onto a flow chart diagram to ensure they read prior to the experiment session. Requirements of the course, assessment and exposure of the lab experience are sufficient to equip students accordingly. Pharmaceutical Chemistry Lab for Bach. Pharmacy encompasses 10\% of assessment in a three-credit unit course, equally with pre-lab questions, data sheets and post-lab questions. Sheeran and Barnes, as cited by Rowell (1997, p. 33) stated that lab reports are assessed in three areas:

- $\quad$ the validity of experiments,

- $\quad$ clarification of students' thinking,

- $\quad$ apprenticing students to the scientific community

However, if the lab manuals already contain expected results so that students only need to follow its instructions and confirm its concepts, the validity of assessment marks given for undergraduate Pharmacy programme students is questionable. Does the mark they obtained reflected their true effort in critical analysis, build their confidence, and promote effective contribution to the overall learning in the course? Students from the preuniversity programme who enrolled in the undergraduate Pharmacy programme were also observed to have lost their skills of writing and analytical thinking as they depended much on the lab manual. Students may not have seen the real purpose and value of the practical work, hence limiting students' preparedness of the practical sessions (Reid and Shah, 2007). Most may have only answered the lab questions without reflecting on the lab experiences as demanded of the course (Rovira-Figueroa, 2009). The focus of students in the course was to complete the task rather than interpret or present their results effectively, bringing into question the skills and knowledge they actually received at the end of the course.

\section{Methodology}

Students of the study consisted of 39 from the Foundation in Science programme, and another 243 of the undergraduate Pharmacy programme. Students who participated in this study were informed of the objectives of the research, and consent was obtained from the Dean of Pharmacy, the Director for the Centre for Foundation in Science Studies as well as lecturers involved in the teaching of lab sessions. All lab reports collected and analysed were with the consent of the respective lecturers.

A questionnaire was adapted from Ryan, Bonanno, Krass, Scouller and Smith (2009) and Del Carlo and Bodner (2004) who respectively initiated researches among postgraduate and undergraduate Pharmacy students in terms of writing of lab reports and its effect on performance. Responses were based on a five-point Likert scale: $1=$ strongly disagree, $2=$ disagree, $3=$ not sure, $4=$ agree, $5=$ strongly agree. All descriptive statistics were analysed using SPSS version 19.

\section{RESULTS AND DISCUSSION}

Research question 1: To what extent is writing Chemistry lab report helpful to pre-university and undergraduate Pharmacy students?

A Pearson correlation test revealed that the mean + SD distribution of students who found writing lab reports enhance their learning was not statistically different between male and female $(3.58+0.97,3.48+0.84)$ respectively, as well as between students in different cohorts; Foundation in Science $(3.51+0.91)$; Bachelor of Pharmacy Year $1(3.65+0.75)$; Bachelor of Pharmacy Year $2(3.53+0.76)$; Bachelor of Pharmacy Year $3(2.97+$ 1.2); Bachelor of Pharmacy Year 4 (3.65 + 0.74).

A Person correlation test further revealed that the mean + SD distribution of students who agreed that the laboratory reports helped them to prepare for their laboratory exams was statistically significant between students in different cohorts, $\mathrm{p}<0.01$; Foundation in Science $(3.05+1.10)$; Bachelor of Pharmacy Year $1(3.63+0.77)$; Bachelor of Pharmacy Year $2(3.63+0.87)$. 
To compare the results between students in the Foundation in Science programme and Year 1 and Year 2 students in undergraduate Pharmacy, both male and female students showed a mean of between 3.45 and 3.54 respectively. A random inspection revealed that undergraduate students in both years of study scored between 0 and 8 (full marks $=10$ ) in the lab exam, with the average being 3.9. By cohort, the students in the Foundation in Science programme indicated that they were unaware that the lab report helped them in preparing for lab exams.

Research question 2: Does Chemistry lab reports assist pre-university and undergraduate Pharmacy students in disciplinary writing and critical analysis?

Hilosky, Sutman, and Schmuckler (1998) referred to undergraduate Chemistry as verifying the already established conclusions or following the "cookbook formula" (Gallet, 1998, p.72), denying students' imagination and initiative. Such cookbooks explain the number of units of each substance required in order to achieve a target result, apart from demonstrating the combination of elements or molecules and the resulting elements or molecules (Kurtus, 2004). It is beyond doubt that the provision of a lab manual for each student is to provide proper preparations prior to an experiment. Chemistry at the beginning college level encourages students to make connections between experimental work and the related chemistry. The cookbook formula as found in the lab manual of this study did not encourage what students should do after the data was collected (Monteyne and Cracolice, 2004). Hilosky, Sutman, and Schmuckler, (1998) emphasised that the lab manual in general guides students to (a) read and follow directions to carry out the experiment and answer the pre-lab questions provided (b) perform the procedures as outlined in the lab manual (c) make observations and record the data related to the observations, and (d) answer questions related to the data obtained.

This study has found that instead of making quality observations and relating lab results to the concepts already established, as well as finding reasons to explain the outcomes of experiments, students generally spent time only completing the laboratory activity and producing the required lab report in order to earn a grade. The skill of maintaining careful records of observations and thinking at the "formal operational cognitive level" (Hilosky, Sutman, and Schmuckler, 1998, p.102) was not seen among samples of the lab reports analysed for this study. Table 3 demonstrates the frequency of responses by all participants of this study regarding the elements of lab reports with which they had difficulties.

Table 1

Frequency of responses to difficulties when writing a lab report

\begin{tabular}{|l|c|c|}
\hline Sections of lab report/ Frequency & $\mathbf{( N = \mathbf { 2 8 4 } )}$ & Percentage \\
\hline Title & 7 & 2.5 \\
\hline Purpose/ Objectives & 19 & 6.7 \\
\hline Apparatus/ Chemical & 12 & 4.2 \\
\hline Procedure & 25 & 2.8 \\
\hline Introduction/ Background information & 58 & 37.0 \\
\hline Result & 105 & 91.2 \\
\hline Discussion & 259 & 29.2 \\
\hline Conclusion & 83 & 9.2 \\
\hline References & 26 & 2.8 \\
\hline Others: & & 0.4 \\
Questions & 8 & 0.4 \\
Major sources & 1 & 0.4 \\
Interaction between chemicals & 1 & 0.4 \\
Unable to find right result & 1 & 0.4 \\
Anything that is too long and not relevant & 1 & \\
Calculation & 1 & \\
\hline
\end{tabular}

From Table 1, it was found that the highest frequency is related to completing the Discussion section of the lab report (90.6\%), despite guidance, pre-lab discussions, availability of the lab manual as well as references. This is followed by the Result section (36.7\%), in which students were clearly unable to relate the theory of chemistry to the outcome of the experiment, or the data obtained, leading to problems in linking theory and data. There is consistency in the results as shown earlier, in which Result, Discussion and Conclusion sections posed problems in writing a lab 
report, further supporting Hilosky, Sutman, and Schmuckler's (1998) earlier statement that the skill of maintaining records of observation is seriously lacking. This also endorses Monteyne and Cracolice's (2004) theory that following the "recipe" in chemistry cookbooks does not promote to students the next step to take.

Most often, the lab reports that students produced indicated a weak link between their observations and data with the Chemistry that took place. The existence of lab manuals already provided the much needed answer, however wrong or derailed the experiment that took place. Students who obtained a different result from the experiment still reported the correct answer, as found in the lab manual and other sources they found, especially those that supplied the answers in the form of a chemical theory to explain their observations. Higher level questions in the Bloom's (1956) Taxonomy, for example "explain", "justify", "analyse" (Churches, 2008) were often met with difficulty; a majority of the students were not able to answer or merely regurgitated the procedure of the experiment instead. Critical analysis had not been developed through writing the lab report; although memory skills were commendable. Reid and Shah (2007) and Rudd, Greenbowe, and Hand (2001) further advocated that laboratory activity at undergraduate level does not promote observation, measurement, prediction, interpretation skills, or how a theory is confirmed. As such, students have retained little of what they learned and have difficulty applying what they know (Gallet, 1998). It is most feared that the current approach to lab reports has led students to be akin to Gallet's (1998) reference of his students being good cooks, but not good scientists (p.72).

Research question 3: Is the mark given for a lab report a fair assessment of pre-university and Pharmacy students' work?

Kirschner and Meester, as cited in Reid \& Shah (2007) outlined the following objectives suitable for a laboratory activity that is worth assessing students' work:

1. to formulate of hypotheses

2. to solve problems

3. to use knowledge and skills in unfamiliar situations

4. $\quad$ to design of simple experiments to test hypotheses

5. $\quad$ to use laboratory skills in performing experiments

6. $\quad$ to interpret experimental data

7. to describe clearly the experiment

8. to remember the critical data of an experiment over a significantly long period of time (p.175)

The validity and reliability of a grade or mark given to a lab report in undergraduate Pharmacy programme is questionable, especially when all results are provided in the lab manual. Students did not share the actual findings from the experiment but instead used the one available in books, on the Internet or the lab manual itself. A random record of grades received by students in this study ranged from 25 to 28 (full marks $=30$ ) regardless of the amount of elaboration given from one student to another. A report may contain very detailed explanation whereas another may lack some information crucial in explaining the concept; however, the latter received a higher mark. Similarly, heavy lifting from the Internet to complete the Discussion section of the report received full marks even though the discussion contained elements not dealt with during theory and pre-lab session (Sharifah, Ismin, Farah and Saheera, 2012).

Hilosky, Sutman, and Schmuckler (1998) in their research, emphasised that assessment of students' lab reports was based on the following criteria: (a) the overall completeness of the report (i.e., the number of questions answered), (b) evidence that the student was present to conduct the experiment, and (c) percent yield or percent error (p.102).

To them, grading on a scale between 1 and 10 is insufficient to grade students' thorough work if they met the criteria above, instead the mark should be increased to reflect students' actual effort and production. In contrast, students in the researchers' study hardly portrayed "completeness" when they submitted their reports, or when all results of observation were perfect even if the actual experiment was contaminated or contained errors. These students still gained almost full assessment marks for the course. Table 1 showed the percentage of students who admitted that they had difficulty in the questions and completing the Discussion section of the lab report despite all 
available references. According to Prince (2006), a mark assigned to a student should be reliable and valid, in addition to exposing students to providing information and deducing results based on materials presented by the instructor during a lab experience. The goal should be to gradually detach the students away from being too reliant on instruction as their primary sources of information, and turning them to become self-learners.

\section{CONCLUSION}

This study investigated the need for writing lab reports in Chemistry among pre-university students as well as undergraduates of the Bachelor of Pharmacy programme. Essentially, all courses of Chemistry in higher education require students to produce lab reports as part of developing disciplinary writing and critical analysis. Students at this stage are exposed to the practical aspects of lab experiments, literally encouraging them to practice and develop techniques and skills. It is to help them rediscover the theory and to some extent, proofing. Students in this study were all equipped with a lab manual and with computer technology at their fingertips for further referencing and research; in addition to the lecture and pre- and post-lab assignments.

The findings of this study have shown that students thought that writing of lab reports did not help them much in the lab exam. Lab manuals that are provided to the students have trained them well to be followers of instruction, to verify the already proven conclusion with lesser need to be critical thinkers and good observers, or to grow new respect for the course. The researchers believe that the current lab report requirement is no longer suitable; there is little or no initiative spurred in finding answers from other trusted sources, and much to lecturers' dismay, the occurrence of plagiarism in the writing is rampant. Despite making references from the lab manual and the Internet, students found the Result and Discussion sections very challenging. One can only lead a horse to the water.

Submitting lab reports had become another duty for students to do, in order to gain a percentage to help them in the overall academic grade. As such, it has denied the experience to be engaged in further discussions or development of higher order thinking; the much needed skills as future pharmacists (Hilosky, Sutman, and Schmuckler, 1998; Monteyne \& Cracolice, 2004; Rudd, Greenbowe \& Hand, 2002). Marking was not consistent, and most lab reports were not returned or given back without comments or feedback. The allocation of marks was minimal, unlike Chemistry in the Pre-university level. In short, lack of a grading scheme, low allocation of marks, and lab reports not returned or returned without feedback all contributed to poor perception of the lab report requirement and wide use of the Internet and irrelevant discussions among Pharmacy students (Sharifah, Ismin, Farah, and Saheera, 2012).

\section{RECOMMENDATIONS}

This study offers a re-crafting of the lab report procedure that can be adapted by all students in the institution. Gallet (1998) suggested the idea of "problem-solving teaching" (p. 73), which is highly used in most secondary schools, colleges, and universities in Canada. Students are given a problem to solve, and are expected to search, investigate, make decisions, and most importantly, work in a team, in order to find solutions. Students cannot passively receive information from the lecturer or other students; they need to be assertive in gathering and exchanging new information with other members.

At the researchers' faculty, a new set of lab sheets was introduced to reduce the amount of information so readily available in the lab manual (see Appendixes 1 \& 2) Such data sheets, given as pre- and post-lab experiments, are to help students be more alert to the data to be collected, conduct the experiment, and be critical of how to discuss it in the lab report later on. This then is followed by a mini viva session, in which key questions pertaining to the experiment are posed - for example questions on reaction based on the related chemical theory, - and giving justification of their answers. A 1 year trial conducted with Year 1 and Year 2 Pharmacy students has shown positive acceptance of the new lab sheet, with more tangible input based on what actually occurred in the lab. This augurs with the findings from Hilosky, Sutman, and Schmuckler (1998), who called this technique the "final oral examination of understandings from the laboratory experiences" (p. 103). This technique promotes a chance for students to develop higher-order thinking and at the same time refine the skill as they progress. It also develops students' self-motivation to learn further, apart from developing a deep approach to learning, with probing, questioning and exploring all done by the students. 
This study proposes that reforms are needed to allow better acceptance of laboratory experience, which should be well nurtured and developed. To be a pharmacist, one should write and think like a true pharmacist. Lab reports are the essence of science and discovery, as a source of reference, just as a dictionary is to a student learning English or a lawyer referring to past cases. Changes in the execution should be promoted-students are given partial information of the lab experiment, to only include Objectives and Purpose. As practiced in the pre-university level, Pharmacy students should also be required to submit a copy of the results obtained during the lab session to avoid unnecessary and irrelevant information. More emphasis should be placed on the importance of skills development in scientific writing, rather than the assigned grade, to divert students' over-focus of academic performance solely.

\section{AUTHOR INFORMATION}

Ismin Izwani Zainol Abidin - a senior lecturer for the Faculty of Pharmacy. She holds a Bachelor in Chemistry and Mathematics and M.Sc in Pharmaceutical Analysis and is currently actively involved with the improvement of curriculum design and I.S.O. academic documentations at the faculty. Her passion is sharing of knowledge and developments of pedagogy. She is currently pursuing $\mathrm{PhD}$ in Medicinal Chemistry. E-mail: ismin@cybermed.edu.my

Sharifah Fauziah Hanim Syed Zain - a senior lecturer at the Centre for Languages and General Studies, currently teaching English for Special Purposes to undergraduate students of MBBS and Pharmacy. She has been involved in teaching for the past 22 years, 14 of which were adult learners. Her keenness involves education management, instructional design and pedagogy. She holds a $\mathrm{PhD}$ in Curriculum and Instruction. E-mail: fauziah@cybermed.edu.my (Corresponding author)

Farah Eliza Mohamad Rasidi - an assistant lecturer, teaching Chemistry for the Foundation in Science programme. She holds with a degree in Engineering and has M.Sc in Chemical Engineering. Her passion includes teaching and research and development. E-mail: farah@cybermed.edu.my

Saheera Kamarzaman - a lecturer in the Faculty of Medicine, teaching Anatomy to MBBS students. She holds B.Sc in Biomedicine (Hon), Graduate Diploma in Human Biology and M.Sc. in Anatomy and Human Biology. Currently pursuing her PhD in Reproductive Toxicology. E-mail: saheera@cybermed.edu.my

\section{REFERENCES}

1. Alaimo, P., Bean, J., Langenhan, \& J., Nichols, L. (2009). Eliminating lab reports: A rhetorical approach for teaching the scientific paper in sophomore organic chemistry. The WAC Journal, 20, 17-32.

2. Atherton, J. S. (2010). Learning and teaching: Constructivism in learning. Retrieved from http://www.learningandteaching.info/learning/constructivism.htm

3. Aurora, T. (2010). Enhancing learning by writing laboratory reports in class. Brief Communications. 24(1), 35-36.

4. $\quad$ Bloom, B. S. (1956). Taxonomy of educational objectives: Handbook 1: Cognitive domain. New York, NY: McKay.

5. Bloom, B. S., Hastings, J. T., \& Mandaus, G. F.(1971). Handbook on formative and summative evaluation of student learning. New York, NY: McGraw-Hill.

6. Brooks, J. G., \& Brooks, M. G. (1999). In search of understanding; The case for constructivist classroom, with a new introduction by authors. Alexandria, VA: Association for Supervision \& Curriculum Development.

7. Churches, A. (2008). Bloom's taxonomy Bloom's digitally. Retrieved from http://www.techlearning.com/showArticle.php?articleID=196605124

8. Cooper, J. (1993, May). Paradigm shifts in designated instruction: From behaviourism to cognitivism to constructivisim. Educational Technology, 12-19.

9. De Carlo, D., \& Bodner, G. (2004). Students' perceptions of academic dishonesty in the chemistry classroom laboratory. Journal of Research in Science Teaching, 41(1), 47-64.

10. Gallet, C. (1998). Problem-solving teaching in the chemistry laboratory: Leaving the cooks... Journal of Chemical Education, 75(1), 72-77. 
11. Ivie, S. (1998). Ausubel's learning theory: An approach to teaching higher order thinking skills. High School Journal, 82(1), 35-44.

12. Hein, K. (1991). Constructivist learning theory. Retrieved from http://www.exploratorium.edu/IFI/resources/constructivistlearning.html

13. Hilosky, A., Sutman, F., \& Schmuckler, J. (1998). Is laboratory-based instruction in beginning collegelevel chemistry worth the effort and expense? Journal of Chemical Education, 75(1), 100-104.

14. Joyce, B., Weil, M., \& Calhoun, E. (2009). Models of teaching ( $8^{\text {th }}$ ed.). New York, NY: Pearson.

15. Kurtus, R. (2004). Chemical equations. Retrieved from http://www.school-forchampions.com/chemistry/equations.htm

16. Licata, K. (1996). Narrative lab reports. The Science Teacher, 66(3), 20-22.

17. Ministry of Education Malaysia (2005). Integrated curriculum for secondary schools. Chemistry Form 5. Retrieved from http://www.moe.gov.my/bpk/v2/index.php

18. Monteyne, K. \& Cracolice, M. (2004). What's wrong with cookbooks? A reply to Ault. Journal of Chemical Education, 81(11), 1559-1560.

19. Porter, R., Guarienti, K., Brydon, B., Robb, J., Royston, A., Painter, H., Sutherland, A., Passmore, C., \& Smith, M. (2010). Writing better lab reports. The Science Teacher, 77(1), 43-48.

20. Prince, M., \& Felder, R. (2006). Inductive teaching and learning methods: Definitions, comparisons, and research bases. Journal of Engineering Education, 95(2), 123-138.

21. Reid, N., \& Shah, I. (2007). The role of laboratory work in university chemistry. Chemistry Education Research and Practice, 8(2): 172-185.

22. Rowell, P. (1997). Learning in school science: The promises and practices of writing. Studies in Science Education, 30, 19-56.

23. Rovira-Figueroa, N. (2009). Assessing the factors that affect the way(s) high school chemistry students write effective laboratory reports (Master's thesis). Available from Dissertation Express database (UMI no: 1470167).

24. Rudd, J., Greenbowe, T., \& Brian, H. (2002). Recrafting the general chemistry laboratory report. Journal of College Science Teaching, 31(4), 230-234.

25. Ryan, G., Bonanno, H., Krass, I., Scouller, K. \& Smith, L. (2009).Undergraduate and postgraduate pharmacy students' perceptions of plagiarism and academic honesty. American Journal of Pharmaceutical Education, 73(6), Article 105:1-8

26. Seddon, G. M., (1978). The properties of Bloom's taxonomy of educational objectives for the cognitive domain. Review of Educational Research, 48(2): 303 - 323.

27. Shah, I., Riffat, Q., \& Reid, N. (2007). Students' perceptions of laboratory work in chemistry at school and college in Pakistan. Journal of Science Education, 8(2), 75-79.

28. Sharifah F., Ismin, I., Farah, E., \& Saheera K. (2012). I found it on the Internet - the copy/ paste habit among undergraduate pharmacy students in chemistry lab report. Paper presented at $24^{\text {th }}$ Federation of Asian Pharmaceutical Association Congress (FAPA), Bali, Indonesia. 
APPENDIX 1 - pre lab data sheet

\begin{tabular}{|lll|l|l|}
\hline Name & Matric No. : \\
\hline
\end{tabular}

Laboratory Practical 2

PRE- LAB QUESTIONS

\section{Beer's Law and Standard Curves}

1. Fill in the table found in the Procedure section, step 2.

\begin{tabular}{|llllllll|}
\hline Test Tube & 1 & 2 & 3 & 4 & 5 & 6 & 7 \\
\hline Dye Volume & 0 & 0.5 & 1 & 1.5 & 2.0 & 2.5 & 3 \\
Water Volume & 3 & & & & & & 0 \\
\hline Total & 3 & 3 & 3 & 3 & 3 & 3 & 3 \\
\hline Dye Concentration $(\mu \mathrm{M})$ & 0 & & & & & & 46.8 \\
\hline
\end{tabular}

2. Why is a rose red?

3. In a chemical compound, what is actually absorbing the light energy?

4. What do you use to measure the absorbance of light?

5. Refer to Figure 2. A substance absorbs with a value of 0.45 . What is the concentration in $\mathrm{mM}$ ?

6. What is the difference between a volumetric pipette and a serological pipette? 
APPENDIX 2 - post lab data sheet

\begin{tabular}{|llll}
\hline Name $\quad: \quad$ Matric No. & : \\
\hline
\end{tabular}

Laboratory Practical 2

POST- LAB QUESTIONS

Beer's Law and Standard Curves

1. Explain the general relationship between absorbance and \% $\mathrm{T}$.

2. State the reason why it is necessary to wipe the cuvettes.

3. State the reason why the wavelength of maximum absorbance is used to analyze chemicals.

4. What is a blank and why is it necessary?

5. The Beer's Law can be used to calculate the concentration of a substance based upon its absorbance. Why then, are you going to the trouble of constructing a standard curve that relates concentration to absorbance?

6. You measured the absorbance of a solution of NADH in a cuvette $1 \mathrm{~cm}$ in path length and found it to be 0.75. If the extinction coefficient of NADH is $6220 \mathrm{M}^{-1} \mathrm{~cm}^{-1}$, what is the concentration of NADH in this solution? Show your work.

7. Which method of determining your unknown would be more reliable: reading a value from your graph or calculating using a computer program? Explain your answer. 